\title{
ĐÁNH GIÁ KẾT QUẢ ĐIỀU TRỊ BỆNH PAGET VÚ TẠI BỆNH VIỆN K
}

\author{
Nguyễn Khắc Tiến ${ }^{1}$, Lê Hồng Quang² , Vũ Đình Giáp ${ }^{1}$, \\ Đoàn Thị Hồng Nhật ${ }^{3}$, Nguyễn Văn Huy ${ }^{2}$
}

\section{TÓM TẮT}

Paget vú là môt loai ung thư hiếm gặp liên quan đến da của núm vú và quâng vú, chiếm khoảng 14,3\% trong các ung thư vú, chủ yếu gặp ở nữ. Bệnh biểu hiện như một Eczema ở quâng vú và núm vú, điều trị chủ yếu là phẫu thuât. Mục tiêu: Mô tả một số đặc điểm lâm sàng, cận lầm sàng và đánh giá kết quả điều trị của bệnh nhần Paget vú tại bệnh viện $K$. Đối tượng và phương pháp nghiên cứu: 46 người bệnh được chẩn đoán và điều trị Paget vú tại bệnh viện $\mathrm{K}$ từ $01 / 2016$ đến 12/2020. Phương pháp nghiên cứu: thu thập số liệu thông tin thứ cấp trên 42 hồ sơ bệnh án; khám và hỏi trên 4 người bệnh. Kết quả: ngứa/đau/rát ở vú $(76,1 \%)$, loét núm vú $(65,2 \%)$, đỏ da ở vú $(45,7 \%), 30,4 \%$ tự sờ thây có khối u vùng ngực. $50 \%$ phát hiện khối u vú trên siêu âm. 52,2\% có tổn thương trên X-quang. Tế bào học: $47,8 \%$ ác tính. Tỉ lệ tái phát $10,9 \%$; sống thêm toàn bô 5 năm $91,3 \%$; sống thêm không bênh 5 năm là $84,8 \%$. Thời gian sống thêm trung bình 55,4 tháng.

Tư khóa: Paget vú; ung thư vú.

\section{SUMMARY}

\section{ELEVATING THE RESULTS OF TREATMENT PAGET'S DISEASE OF THE BREAST IN K HOSPITAL}

Paget's disease of the breast is a rare cancer, which is related to the nipple, areola complex, accounting for $1-4,3 \%$ of all the breast carcinomas. Paget's disease is more frequent in women. It presents as an Eczema at the nipple areola, the main treatment is surgery. Objective: To describe some clinical and subclinical characteristics and elevate the results of treatment Paget's disease of the breast in $\mathrm{K}$ hospital. Patients and methods: 46 patients with Paget's disease of the breast in K hospitalfrom January 2016 to December 2020. Method: Data collection on 42 records and 4 patients. Results: Itching/pain/ burning in the breast $(76.1 \%)$, nipple ulcer $(65.1 \%)$, red skin in the breast $(45.7 \%), 30.4 \%$ palpable breast lump. $50 \%$ detect breast tumor on ultrasound. $52.2 \%$ had lesions on X-ray. Cytology: $47.8 \%$ malignant. Recurrence rate $10.9 \%$; Overall 5 -year survival $91.3 \%$; 5-year disease-free survival $84.8 \%$. Average survival time 55.4 months.

Keywords; Paget's disease; breast cancer

\footnotetext{
${ }^{1}$ Bệnh viện Ung bướu Nghệ An

${ }^{2}$ Bệnh viện $K$,

${ }^{3}$ Trường Đại học Y Khoa Vinh

Chịu trách nhiệm chính: Nguyễn Khắc Tiến

Email: khactien01@gmail.com

Ngày nhận bài: 14.9.2021

Ngày phản biện khoa học: 8.11.2021

Ngày duyệt bài: 19.11.2021
}

\section{I. ĐẶT VẤN ĐỀ}

Bệnh Paget là một loại ung thư hiếm gặp chiếm khoảng 1-4,3\% trong tổng số người bệnh bị ung thư vú, được nhà phẫu thuật người Anh Jame Paget lân đầu tiên mô tả vào năm 1874 . Bệnh Paget có nhiêuu dạng biểu hiện ở các vị trí khác nhau, được chia làm 2 thể chính là Paget tại vú và Paget ngoài vú. Trong bệnh Paget vú, chẩn đoánđa phân dựa vào đặc điểm lâm sàng và mô bệnh học. Ở giai đoạn sớm, điều trịchủ yếu dựa vào phẫu thuật, trong đó phẫu thuật cắt toàn bộ tuyến vú kèm kiểm tra hạch nách là phương pháp điêu trị cơ bản. Xạ trị cần thiết với các trường hợp bảo tồn vú, ung thư vú có di căn hạch. Hóa trịđược áp dụng cho các trường hợp giai đoạn muộn hơn, có khối ung thư xâm lấn kèm theo ở phía dưới.

Khoảng 80-90\% các trường hợp bệnh Paget vú có liên quan đến một ung thư biểu mô cơ bản: ung thư nội ống tại chỗ hoặc ung thư xâm nhập. Các triệu chứng lâm sàng, hình ảnh mô bệnh học của bễ̂nh Paget vú rất dễ nhâm lẫn với các bệnh da liễu nên thường được chẩn đoán nhầm dẫn đến thời gian diến biến của bệnh thường kéo dài trước khi được chẩn đoán xác định. Nhiều người chỉ đi khám khi bệnh đã quá nặng khi các khối u di căn khiến việc điều trị khó khó khăn, nguy cơ tử vong cao.

Tại Việt Nam có rất ít các nghiên cứu về bệnh Paget vú. Vì vậy, nhằm góp phân nâng cao chẩn đoán và điều trị bệnh Paget vú, chúng tôi tiến hành nghiên cứu: "Đánh giá kêt quả điều trị bệnh Paget vú tại Bệnh viện K"với các mục tiêu:

Mục tiêu 1: Nhận xét một số đặc điểm lâm sàng, cận lâm sàng của bệnh nhân Paget vú tại bệnh viện $K$

Mục tiêu 2: Đánh giá kết quả điều trị bệnh Paget vú tại Bệnh viện K

\section{II. ĐỐI TƯợNG VÀ PHƯƠNG PHÁP NGHIÊN CỨU \\ 1. Thời gian và địa điểm nghiên cứu}

Thời gian: Từ tháng 01/2016 đến hết tháng 12/2020.

- Địa điểm: Bệnh viện K

2. Đối tượng nghiên cứu

- Tiêu chuẩn lựa chọn đối tượng nghiên cứu:

+ Người bệnh được chẩn đoán là Paget vú

+ Mô bệnh học là Paget tuyến vú.

+ Không mắc ung thư thứ hai. 
+ Có đầy đủ hồ sơ lưu trũ.

3. Phương pháp nghiên cứu

Thiết kế nghiên cứu: Mô tả cắt ngang, hồi cứu kết hợp tiến cứu.

4. Chọn mẫu và cõ̃ mẫu: Chọn cõ mẫu thuận tiện, $n=46$ người bệnh.

5. Công cụ và kỹ thuật thu thập số liệu

- Công cư: Bệnh án nghiên cứu thiết kế sẵn.

- Thu thập số liệu:

+ Hồi cứu hồ sơ bệnh án: 42 người bệnh.

+ Hỏi và khám trực tiếp những người bệnh đang điều trị tại bệnh viện kết hợp thu thập thông tin từ hồ sơ lưu trữ: 04 người bệnh.

6. Khống chế sai số

- Tất cả người bênh được lưu trữ đầy đủ bằng bệnh án nghiên cứu và trên máy tính.

- Điểu tra viên được tập huấn và sử dụng bệnh án nghiên cứu phỏng vấn.

7. Xử lý số liệu: Các số liệu thu thập được nhập và xử lý bằng phần mềm thống kề $Y$ học SPSS 20.0, Excel và Word.

8. Đạo đức nghiên cứu: Nghiên cứu được thông qua đề cương bởi hội đồng khoa học bệnh viện $\mathrm{K}$ và bộ môn Ung thư trường Đại học $Y$ Hà Nội trước khi tiến hành nghiên cứu. Thông tin của người bệnh nghiên cứu được bảo đảm giữ kín và chỉ dùng cho mục đích nghiên cứu.

\section{KẾT QUẢ NGHIÊN CứU}

Bảng 3.1. Đặc điểm lâm sàng và cận lâm sàng

\begin{tabular}{|c|c|c|}
\hline Đặc điểm & $\begin{array}{c}\text { Số } \\
\text { lượng }\end{array}$ & $\begin{array}{c}\text { Tỉ lệ } \\
\%\end{array}$ \\
\hline $\begin{array}{c}\text { Triệu chứng cơ năng } \\
\text { Loét núm vú } \\
\text { Đau rát núm vú } \\
\text { Chảy dịch/máu núm vú } \\
\text { Sờ thấy khối u vùng } \\
\text { ngực }\end{array}$ & $\begin{array}{l}30 \\
35 \\
22 \\
14\end{array}$ & $\begin{array}{c}65,2 \\
76,1 \\
47,82 \\
30,4\end{array}$ \\
\hline $\begin{array}{l}\text { Siêu ầm vú } \\
\text { U vú kèm theo }\end{array}$ & 23 & 50 \\
\hline $\begin{array}{l}\text { Chụp mamography vú } \\
\text { Tổn thương trên } \\
\text { mamography vú }\end{array}$ & 24 & 52,2 \\
\hline $\begin{array}{c}\text { Tế bào học vị trí tốn } \\
\text { thướng } \\
\text { Ác tính } \\
\text { Nghi ngờ } \\
\text { Lành tính }\end{array}$ & $\begin{array}{l}22 \\
10 \\
14\end{array}$ & $\begin{array}{l}47,8 \\
21,8 \\
30,4\end{array}$ \\
\hline
\end{tabular}

Nhận xét: Triệu chứng cơ năng phổ biến nhất bao làđau rát núm vú $(76,1 \%)$, loét núm vú $(65,2 \%)$, có $30,4 \%$ người bệnh sờ thấy có khối u vùng ngực. $50 \%$ người bệnh Paget vú phát hiện có khối u vú kèm theo trên hình ảnh siêu âm và $52,2 \%$ người bệnh có hình ảnh tổn thương bất thường trên phim chụp mamography vú. Tỉ lệ người bệnh có kết quả xét nghiệm tế bào học ác tính tai vị trí tổn thương là 47,8\%.

Bảng 3.2. Đánh giá kết quả điều trị

\begin{tabular}{|c|c|c|}
\hline Kết quả & $\begin{array}{c}\text { Số } \\
\text { lượng }\end{array}$ & $\begin{array}{c}\text { Tỉ lệ } \\
\text { \%o }\end{array}$ \\
\hline Tỉ lệ tái phát & 3 & 10,9 \\
\hline Kết quả theo dõi & & \\
Còn sống không bệnh & 39 & 84,8 \\
Còn sống có tái phát & 3 & 6,5 \\
Đã tứ vong & 4 & 8,7 \\
\hline Thời gian sống thêm & & \\
1 năm & 45 & 97,8 \\
2 năm & 44 & 95,7 \\
3 năm & 43 & 93,5 \\
4 năm & 43 & 93,5 \\
5 năm & 42 & 91,3 \\
\hline
\end{tabular}

Nhận xét: Tỉ lệ có tái phát sau điều trị là $10,9 \%$, tất cả các tái phát này đều có di căn. Tỉ lệ sống thêm không bệnh 5 năm là $84,8 \%$. Tỉ lệ sống thêm sau 5 năm điều trị ở đối tượng nghiên cứu là 91,3\%.

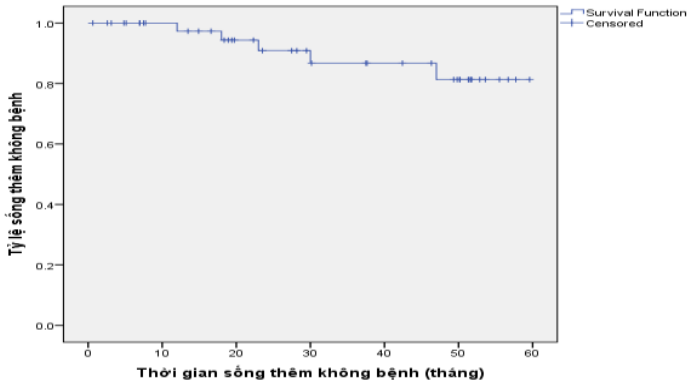

Biểu đồ 3.1. Thời gian sông thêm không bệnh

Nhân xét: Thời gian sông thêm không bệnh trung bình $53,9 \pm 2,4$ tháng. Tỉ lệ sống thêm không bệnh kết thúc tại thời điểm nghiên cứu là $89,1 \%$.

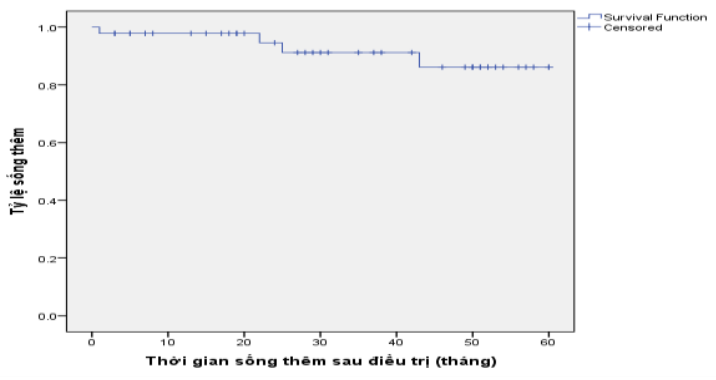

Biểu đồ 3.2. Thời gian sông thêm toàn bộ sau điều trị trong thời gian

Nhânn xét: Thời gian sống thêm toàn bộ sau điều trị trung bình 55,4 tháng.

\section{BÀN LUÂ̂N}

\section{1. Đặc điểm lâm sàng và cận lâm sàng}


Triệu chứng cơ năng: Trong nghiên cứu này, các triệu chứng ngứa/đau/rát ở núm vú/quầng vú/da quanh vú; loét núm vú; đỏ da ở núm vú/quầng vú/da quanh vú là những triệu chứng thường gặp nhất với tỉ lệ lần lượt là $76,1 \% ; 65,2 \% ; 45,7 \%$ (bảng 3.1). Kết quảnày tương tự với nghiên cứu của Kristina Dalberg (2008) trên 223 trường hợp cho thấy hầu hết người bệnh có triệu chứng chàm hoặc loét núm vú với tỉ lệ 98\% [3]. Thống kê trong nghiên cứu này cũng cho thấy có $30,4 \%$ người bệnh tự sờ thấy khối u vú trước khi đến viện. Kết quả này tương tự như nghiên cứu của tác giả Merrill AY (2017) thực hiện trên 14 người bệnh cho thấy có $31 \%$ trường hợp sờ thây khối u ởvú [4]. Như vậy, trên lâm sàng nếu phát hiện các triệu chứng kể trên thì cần nghĩ đến và kiểm tra kỹ để loại trừ bệnh lý Paget.

Siêu âm vú và chụp mamography vú: Kết quả siêu âm vú trong nghiên cứu phát hiện $50 \%$ người bệnh có khối u vú kèm theo, trong đó có tới 30,4\% có từ 2 khối u vú trở lên (bảng 3.1). So với kết quả phát hiện khối u vú qua thăm khám lâm sàng, kết quả siêu âm vú đã giúp phát hiện thêm 10,9\% người bệnh có u vú kèm theo. Theo Yang WT (1997), kiểm tra siêu âm có thể hữu ích và nên được coi là một phần của đánh giá ban đầu, đặc biệt khi hình ảnh chụp phim XQuang vú chưa phát hiện tổn thương; tuy nhiên, hầu hết các phát hiện tổn thương Paget vú trên hình ảnh siêu âm không đặc hiệu và giống với các trường hợp nhiễm trùng [8]. Hình ảnh siêu âm có thể cho thấy sự không đồng nhất của nhu mô, các vùng giảm âm, các khối rời rạc, da dày lên hoặc giãn các ống dẫn. Như vậy, mặc dù siêu âm không cho những hình ảnh đặc hiệu trong bệnh Paget, tuy nhiên, kiểm tra vú qua siêu âm cũ̃ng góp phần giúp bác sĩ có thêm hình ảnh những tổn thương bất thường có thể là hình ảnh Paget vú, có thể là hình ảnh của một bệnh lý nào khác, song việc này sẽ rất có ích trong việc định hướng bác sĩ điều trị có những chỉ định để xác định tổn thương. Do vậy, tầm soát các tổn thương bệnh Paget qua siêu âm vẫn nên thực hiện thường quy ở người bệnh có những triệu chứng cơ năng trên vú, bởi dù sao, siêu âm cũng là một xét nghiệm có chi phí có giá thành rẻ giúp người bệnh có thể phát hiện tổn thương bất thường ở vú. Kết quả chụp X-Quang vú trong nghiên cứu cho thấy có $52,2 \%$ có hình ảnh tổn thương mamography ở vú (bảng 3.1). Theo Karamchandani DM và cộng sự (2019) chụp nhũ ảnh thường quy được thực hiện trong các trường hợp nghi ngờ bệnh Paget để xác định các vi vôi hóa, độ mờ không đồng nhất và nghi ngờ. Tuy nhiên, những phát hiện này có thể khó được phát hiện. Tác giả cũng báo cáo rằng trên lâm sàng khi có khối sờ thây được, độ nhạy của chụp nhũ ảnh để phát hiện khối u là $97 \%$, trong khi đó chỉ là $50 \%$ khi không sờ thấy khối u trên lâm sàng [2]. Mặc dù, chụp X-Quang vú không phải lúc nào cũng là một quy trình đáng tin cậy để phát hiện bệnh Paget vú, tuy nhiên các phát hiện $X$ quang rất quan trọng để đánh giá việc xử trí thích hợp và điều trị của người bệnh.

Tế bào học vị trí tổn thương: Tất cả 46 người bệnh trong nghiên cứu đều được làm xét nghiệm tế bào học tại vị trí tổn thương. Kết quả cho thây $47,8 \%$ người bệnh có tế bào ác tính, tỉ lệ nghi ngờ là $21,7 \%$, và 30,4\% là hình ảnh lành tính (bảng 3.1). Theo báo cáo của Yim JH và cộng sự (1997) đã thây rằng ung thư biểu mô vú tiềm ẩn được tìm thây ở> $90 \%$ người bệnh mắc bệnh Paget [7].

\section{2. Đánh giá kết quả điêu trị}

Tỉ lệ tái phát: Tỉ lệ tái phát trong nghiên cứu này là $10,9 \%$ trong vòng 5 năm sau điều trị phấu thuật cắt toàn bộ vú. Kết quả nghiên cứu của Dixon AR và cộng sự (1991) trên 37 người bệnh Paget vú được điều trị bằng phẫu thuật cắt bỏ vú đơn thuần, tỉ lệ tái phát tại chỗ chỉ là $5 \%$, với thời gian theo dõi trung bình là 40 tháng[1]. Sự khác biệt này có thể do sự khác biệt về cỡ mẫu, cũng như sự khác biệt về đặc điểm của đối tượng nghiên cứu và điều kiện y tế hiện tại tại địa điểm nghiên cứu.

Kết quả sống thêm 5 năm ở người bệnh

Nghiên cứu này tiến hành theo dõi kết quả của 46 người bệnh Paget tại thời điểm kết thúc nghiên cứu. Thời gian theo dõi trung bình mỗi người bệnh là $3,2 \pm 19,1$ tháng. Người bệnh có thời gian theo dõi dài nhất là 60 tháng và ít nhất là 1 tháng. Kết quả nghiên cứu cho thây, tại thời điểm kết thúc nghiên cứu có 4 người bệnh đã tử vong do tất cả các nguyên nhân chiếm 8,7\%. Tỉ lệ còn sống là $91,3 \%$ trong đó tỉ lệ còn sống không bệnh chiếm 84,8\%. Thời gian sống thêm trung bình trong thời gian nghiên cứu là 55,4 tháng. Theo chương trình Giám sát, Dịch tễ học và Kết quả Cuối cùng của NCI, tỷ lệ sống sót sau 5 năm của tất cả phụ nữ ở Hoa Kỳ được chẩn đoán mắc bệnh Paget vú từ năm 1988 đến 2001 là 82,6\%[6].Kết quả nghiên cứu của Sonia OrtizPagan (2011) so sánh ảnh hưởng của bệnh Paget vú đối với sự sống còn của bệnh ung thư vú cho thấy thời gian sống thêm toàn bộ trong 5 năm thấp hơn ở nhóm bệnh Paget vú $(81 \%)$ so với nhóm ung thư vú không có bệnh Paget 
(94\%) (log-rank, p = 0,03) [5]. Tỉ lệ sông thêm sau 5 năm phấu thuật trong nghiên cứu của chúng tôi cao hơn các thống kê trên có thể do sự khác biệt liên quan đến cỡ mẫu. Cõ mẫu trong nghiên cứu của chúng tôi khá nhỏ so với các thống kê trên.

\section{KẾT LUÂN}

\section{1. Đăc điểm lâm sàng và cân lâm sàng}

- Triểu chứng cơ năng thường găp: ngứa/ đau/ rát ở vú (76,1\%), loét núm vú $(65,2 \%)$.

- Tỉ lê phát hiên khối u vú trên siêu âm là 50\%.

- Tỉ lệ phát hiện tổn thương trên X-quang là $52,2 \%$. tính.

- Kết quả xét nghiệm tế bào học: 47,8\% ác

2. Đánh giá kết quả điêuu trị

- Tỉ lệ tái phát 10,9\%.

- Tỉ lệ sống thêm toàn bộ 5 năm 91,3\%.

- Tỉ lề sống thêm không bệnh 5 năm là 84,8\%.

- Thời gian sống thêm trung bình 55,4 tháng.

TÀl LIỆU THAM KHẢO
1. Dixon AR GM, Ellis IO, et al (1991). Paget's disease of the nipple. 34(2), 467-472.

2. Karamchandani DM CA, Riley MP, et al (2015). Pathologic-radiologic correlation in evaluation of retroareolar margin in nipple-sparing mastectomy. Virchows Arch. 466(3), 279-287.

3. Kristina D. HH, Fredrik W (2008). Paget's disease of the nipple in a population based cohort. Breast Cancer Res Treat. 111, 313-319.

4. Merrill AY WA, Howard M (2017). Paget's Disease of the Breast: An Institutional Review and Surgical Management.Am Surg.83(3), 96-98.

5. Ortiz-Pagan S, Cunto-Amesty G, Narayan S, et al (2011). Effect of Paget's Disease on Survival in Breast Cancer: An Exploratory Study. Archives of Surgery. 146(11), 1267-1270.

6. Ries LAG EMea (2012). SEER Survival Monograph: Cancer Survival Among Adults: U.S. SEER Program, 1988-2001, Patient and Tumor Characteristics. Bethesda. National Cancer Institute, SEER Program, 2007 -2012

7. Yim JH WM, Philpott GW, et al (1997). Underlying pathology in mammary Paget's disease. Ann Surg Oncol. 4(4), 287-292.

8. Yang WT KW, Metreweli C (1997). Clinically and mammographically occult invasive ductal carcinoma diagnosed by ultrasound: the focally dilated duct. Australas Radiol. 41(1), 73-75.

\section{SARCOPENIA VÀ MộT SỐ YẾU TỐ LIÊN QUAN TRÊN BÊNNH NHÂN TĂNG HUYẾT ÁP CAO TUỔI}

\section{TÓM TẮT}

Mục tiêu: xác định tỉ lệ sarcopenia và tìm hiểu một số yếu tố liên quan với sarcopenia ở bệnh nhân cao tuổi có tăng huyết áp (THA). Đối tượng và phương pháp: nghiên cứu mô tả cắt ngang trên 105 bệnh nhân có $T H A \geq 60$ tuổi khám và điêu trị tại bệnh viện Lão khoa Trung ương. Đối tượng nghiển cứu được đo khối lượng cơ xương bằng phân tích trở kháng điện sinh học (BIA, máy Inbody 770) và được chẩn đoán sarcopenia dựa vào tiêu chuẩn của Hiệp hội Sarcopenia Châu Á. Kểt quả: Tỉ lệ nam/nữ là $1: 2$; Tuổi trung bình là: $72,76 \pm 7,53$ (năm); Tỉ lệ sarcopenia là: $54,3 \%$ (trong đó tỉ lệ sarcopenia nặng là 23,8\%). Tỉ lệ sarcopenia có liên quan đến tuổi cao, thời gian THA, tiền sử ngã trong 1 năm qua và chỉ số khối cơ thể trung bình. Kết luận: Cứ 2 bệnh nhân

${ }^{1}$ Bệnh viện Trung ương Quân đội 108,

${ }^{2}$ Bệnh viện Lão khoa Trung ương,

${ }^{3}$ Trường Đại học Y Hà Nội

Chịu trách nhiệm chính: Nguyễn Minh Hồng

Email: hongbean8108@gmail.com

Ngày nhận bài: 15.9.2021

Ngày phản biện khoa học: 10.11.2021

Ngày duyệt bài: 18.11.2021
Nguyễn Minh Hồng ${ }^{1}$, Nguyễn Thị Thu Hương, 2,3 , THA cao tuổi có ít nhất một người được chẩn đoán sarcopenia. Sarcopenia có liển quan đến tuổi cao, thời gian THA, tiền sử ngã và chỉ số khối trung bình.

Tư khóa: tăng huyết áp, mất cơ, cao tuổi.

\section{SUMMARY}

SARCOPENIA AND SOME RELATED FACTORS IN ELDERLY HYPERTENSION PATIENTS

Objectives: To evaluate the prevalence of sarcopenia and related factors in elderly hypertension patients. Subjects and methods: A cross-sectional descriptive study was performed in 105 hypertension patients aged 60 years or older, who were treated at the National Geriatric Hospital. All participants were evaluated appendicular skeletal muscle by Bioelectrical impedance analysis (BIA, Inbody 770) and were diagnosed with sarcopenia based on the Asian Working Group for Sarcopenia. Results: The ratio of male/female was $1: 2$; the mean age of subjects was $72.76 \pm 7.53$ (years); the prevalence of sarcopenia was: $54.3 \%$ (with severe sarcopenia: $23.8 \%$ ). Factors associated with sarcopenia were advanced age, duration of hypertension, history of falls and mean BMI. Conclusions: At least one in elderly 2 hypertensive patients is diagnosed with sarcopenia. 